\title{
Carbon Monoxide: An Endogenous Modulator of Sinusoidal Tone in the Perfused Rat Liver
}

\author{
Makoto Suematsu, Nobuhito Goda, Tsuyoshi Sano, Satoshi Kashiwagi, Tsuyoshi Egawa, Yuichi Shinoda, \\ and Yuzuru Ishimura \\ Department of Biochemistry, School of Medicine, Keio University, Tokyo 160, Japan
}

\begin{abstract}
Heme oxygenase is a heme-oxidizing enzyme which generates biliverdin and carbon monoxide $(\mathrm{CO})$. The present study was designed to elucidate whether CO endogenously produced by this enzyme serves as an active vasorelaxant in the hepatic microcirculation. Microvasculature of the isolated perfused rat liver was visualized by dual-color digital microfluorography to alternately monitor sinusoidal lining and fat-storing Ito cells. In the control liver, the $\mathrm{CO}$ flux in the venous effluent ranged at $0.7 \mathrm{nmol} / \mathrm{min}$ per gram of liver. Administration of a heme oxygenase inhibitor zinc protoporphyrin IX $(1 \mu \mathrm{M})$ eliminated the baseline $\mathrm{CO}$ generation, and the vascular resistance exhibited a $30 \%$ elevation concurrent with discrete patterns of constriction in sinusoids and reduction of the sinusoidal perfusion velocity. The major sites of the constriction corresponded to local sinusoidal segments colocalized with Ito cells which were identified by imaging their vitamin $A$ autofluorescence. The increase in the vascular resistance and sinusoidal constriction were attenuated significantly by adding $\mathrm{CO}(1 \mu \mathrm{M})$ or a cGMP analogue 8-bromo-cGMP $(1 \mu M)$ in the perfusate. From these findings, we propose that $\mathrm{CO}$ can function as an endogenous modulator of hepatic sinusoidal perfusion through a relaxing mechanism involving Ito cells. ( $\mathrm{J}$. Clin. Invest. 1995. 96:2431-2437.) Key words: heme oxygenase • nitric oxide • cGMP • Ito cells • microcirculation
\end{abstract}

\section{Introduction}

Carbon monoxide, a product of heme oxygenase (EC 1.14.99.3) $(1,2)$ is thought to up-regulate cGMP via activation of guanylate cyclase, and thereby shares several biological actions with nitric oxide (NO), ${ }^{1}$ such as smooth muscle relaxation (3) or

Address correspondence to Makoto Suematsu, Assistant Professor, Department of Biochemistry, School of Medicine, Keio University, 35 Shinanomachi, Shinjuku-ku, Tokyo 160, Japan. Phone: 81-3-3355-2827; FAX: 81-3-3358-8138.

Received for publication 11 April 1995 and accepted in revised form 11 July 1995.

1. Abbreviations used in this paper: $8 \mathrm{Br}-\mathrm{cGMP}, 8$-bromo-cGMP; $\mathrm{AG}$ aminoguanidine; L-NAME, $N^{\omega}$-nitro-L-arginine methyl ester; Mb, myoglobin; NO, nitric oxide; $\mathrm{PE}$, phenylephrine; ZnPP, zinc protoporphyrin IX.

J. Clin. Invest.

(C) The American Society for Clinical Investigation, Inc.

0021-9738/95/11/2431/07 \$2.00

Volume 96, November 1995, 2431-2437 inhibition of platelet aggregation (4). There is, however, little experimental evidence suggesting that $\mathrm{CO}$ generated endogenously by heme oxygenase activity participates in modulation of cell function under physiologic conditions, except for recent observations which provide evidence for the contribution of $\mathrm{CO}$ as a neural messenger in the brain $(5,6)$. As to its vascular actions, no definite evidence has been provided to establish $\mathrm{CO}$ as an endogenous modulator of vascular tone.

Liver is, like the brain and spleen, one of the most abundant sources of the heme oxygenase among organs (1). We have recently reported that zinc protoporphyrin IX (ZnPP), a potent inhibitor of heme oxygenase, elicited an increase in the perfusion pressure in the rat liver, suggesting that constitutive levels of $\mathrm{CO}$ are necessary to maintain its low vascular resistance (7). The present study was undertaken to explore the microvascular mechanisms through which $\mathrm{CO}$ generated by heme oxygenase modulates the vascular resistance. We have examined the role of Ito cells, liver-specific microvascular pericytes, as a putative CO-sensitive machinery to maintain sinusoidal tone in a relaxing state.

\section{Methods}

Animal preparation. Male Wistar rats (300-320 grams) allowed free access to laboratory chow and tap water were fasted $24 \mathrm{~h}$ before experiments. After the animals were anesthesized with pentobarbital sodium ( $40 \mathrm{mg} / \mathrm{kg}$ intraperitoneally), the livers were perfused with hemoglobin- and albumin-free Krebs-Henseleit bicarbonate-buffered solution

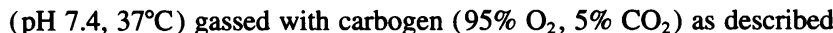
previously $(8,9)$. The common bile duct was cannulated by a PE-10 polyethylene catheter to monitor the bile output every $5 \mathrm{~min}$ after the start of experiments. The perfusate was pumped through the liver with a peristaltic pump at a constant flow rate of $3.4 \mathrm{ml} / \mathrm{min}$ per gram of liver weight in a single pass mode under monitoring the inlet perfusion pressure and the portal and venous oxygen concentrations using oxygen microelectrodes $\left(\mathrm{Po}_{2}-100\right.$; Inter Medical Co., Tokyo, Japan) (10).

Digital microfluorography of hepatic microcirculation. The isolated perfused liver was placed on a plastic stage in which the bottom of the liver was supported by an elastic nylon net to minimize local damages of preparation. The upper surface of the left lobe was covered with a spheroid-shaped cover glass and was observed through an orthostatic fluorescence microscope (TMD; Nikon, Tokyo, Japan) equipped with a $16 \times$ quartz objective lens and an intensified charged couple device camera (TEC-470, Optronics Engineering, Goleta, CA), a gray density filter (ND16; Nikon), and a programing electric shutter (Shutter Controller; Sankei, Inc., Tokyo, Japan ), which allowed us to limit unnecessary exposure to epi-illumination by a xenon lamp ( $100 \mathrm{~W})$. To determine the diameter of hepatic sinusoids and to confirm the state of microvascular perfusion, $2.0 \%$ solution of FITC-BSA was injected into the perfusion circuit at a rate of $250 \mu \mathrm{l} / \mathrm{s}$ for $4 \mathrm{~s}$. The intralobular movement of the fluorescence tracer was visualized by epi-illuminating at $480 \mathrm{~nm}$ with passage through a 530-nm emission filter (BA520; Nikon), and was recorded continuously to a digital videorecorder (SVHS-HQ; Victor-JVC, Tokyo, Japan). By analyzing the replayed videotapes using an off-line digital videodensitometer (Capiflow; IM-Capi- 
flow, Kista, Sweden) $(9,10)$, the intralobular perfusion velocity $\left(\mathrm{V}_{\mathrm{P}-\mathrm{C}}\right)$ was estimated as follows:

$\mathrm{V}_{\mathrm{P}-\mathrm{C}}=\mathrm{L}_{\mathrm{P}-\mathrm{C}} / \Delta \mathrm{T}_{\mathrm{P}-\mathrm{C}} \quad(\mu \mathrm{m} / \mathrm{s})$,

where $L_{P-C}$ is the distance between the centers of the optical measurement windows $\left(50 \times 50 \mu \mathrm{m}^{2}\right)$ in periportal and pericentral regions, and $\Delta \mathrm{T}_{\mathrm{P}-\mathrm{C}}$ is the time delay of the peak intensity between the periportal and pericentral regions which was estimated by the videodensitometer. Since the $V_{P-C}$ values varied among different livers or lobules, ranging from $300 \mu \mathrm{m} / \mathrm{s}$ to $800 \mu \mathrm{m} / \mathrm{s}$, the data were divided by the control velocity at time 0 , and expressed as the normalized velocity as compared with the control $\left(\% \mathrm{~V}_{\mathrm{P}-\mathrm{C}}\right)$.

Evaluation of topographic correlation between Ito cells and sinusoidal constriction. Intralobular distribution of Ito cells was identified by our previous method on the basis of visualization of vitamin A autofluorescence $(10,11)$. Briefly, the liver surface was epiilluminated at $360 \mathrm{~nm}$ by using a narrow band pass filter (BA400; Nikon), and the autofluorescence at $450 \mathrm{~nm}$ was visualized by the intensified charged couple device camera. The camera controller was able to average eight video images in a real-time manner, and the averaged images of vitamin A autofluorescence were automatically introduced into a computer-assisted digital imaging processor (Image 1.53/Quadra 840; Data Translation Inc., Marlboro, MA). This processor also allowed us to superimpose the FITC-BSA microangiograph onto another microfluorograph showing vitamin A autofluorescence, facilitating the correlative analysis between localization of sinusoidal constriction and that of Ito cells. Both FITCBSA and vitamin A images were recorded alternatively by switching over the corresponding filter cubes. To evaluate alterations in the size of a single sinusoid, the diameters in different portions of the sinusoid (interconnecting sinusoids were discarded) were checked using the FITC-BSA-associated microfluorographs. Each measurement was carried out every $10 \mu \mathrm{m}$ from the most efferent site to the afferent portion adjacent to central venule, which gave 30-40 measurements for each sinusoid. At least 20 sinusoids were evaluated in a single experiment. Using the FITC-BSA-associated microfluorographs superimposed on those of vitamin A autofluorescence in the same field, the sites of measurements were divided into two groups; those colocalized with and without vitamin A autofluorescence. Namely, changes in the sinusoidal diameter during experiments were evaluated separately at the regional sinusoidal domains adjacent to, and apart from, Ito cells.

ZnPP administration and interventions. The perfused livers were divided into six subgroups (control, $1 \mu \mathrm{M} \mathrm{ZnPP,} 1 \mu \mathrm{M} \mathrm{CO}+1 \mu \mathrm{M}$ $\mathrm{ZnPP}, 1 \mu \mathrm{M}$ 8-bromo-cGMP [8Br-cGMP] $+1 \mu \mathrm{M} \mathrm{ZnPP}, 1 \mu \mathrm{M} \mathrm{CO}$ alone, $1 \mu \mathrm{M}$ 8Br-cGMP alone; $n=8$ for each group). 20 min after completing the preparation of the perfused liver, FITC-BSA-associated microangiographs and the corresponding vitamin A autofluorographs were recorded in the same microscopic field as control microfluorographs. ZnPP was added to the perfusate reservoir to give a final concentration at $1 \mu \mathrm{M}$. CO- or $8 \mathrm{Br}$-cGMP-containing Krebs-Henseleit buffer was infused into the liver $5 \mathrm{~min}$ before the start of the $\mathrm{ZnPP}$ administration. Every $10 \mathrm{~min}$ after the start of the ZnPP administration, both FITC-BSA and vitamine A microfluorographs were recorded. The total exposure time to record Ito cell images (vitamin A autofluorescence) during the entire course ( $30 \mathrm{~min}$ ) of experiments was within $4 \mathrm{~s}$. Under these conditions, the autofluorescence derived from Ito cells was well maintained with a minimal photobleaching phenomenon until the end of experiment. By epi-illuminating at $360 \mathrm{~nm}$ continuously at the end of each experiment, the autofluorescence in Ito cells was totally eliminated, confirming the rapid photobleaching property of vitamin $\mathrm{A}(10,11)$. Finally, we evaluated time history of oxygen consumption and bile output to confirm the viability of each perfused liver. Our experimental results showed that neither administration of $8 \mu \mathrm{M} C O$ nor its combination with $1 \mu \mathrm{M} \mathrm{ZnPP}$ did elicit a significant reduction of the baseline bile output or oxygen consumption, suggesting the absence of possible noxious effects of these reagents on the perfused liver. When the bile output was reduced to $<1.0 \mu \mathrm{l} / \mathrm{min}$ per gram liver or the oxygen consumption ranged at $<1.8 \mu \mathrm{mol} / \mathrm{min}$ per gram liver during the obser- vation period, such an experiment was discarded to avoid data from low quality preparations which mainly resulted from local perfusion failure.

In another set of experiments, the $\alpha_{1}$-adrenergic receptor agonist phenylephrine ( $\mathrm{PE}$ ) was used as the positive control, since adrenergic nerve endings (12) and catecholamine-mediated constriction are localized to the portal venules in the rat (13). The whole organ vascular resistance in the liver was estimated as the ratio of the pressure gradient between the portal and hepatic veins versus flow volume according to the previous method (14). In some experiments, heterogeneity of the lobular perfusion was macroscopically evaluated to check the difference in the vasoconstrictive mechanism between the ZnPP- and the PE-treated livers. To that effect, $2 \mathrm{ml}$ of the trypan blue solution (3\%) was infused at a rate of $400 \mu \mathrm{l} / \mathrm{min}$ at the end of experiments (15). Other reagents used in the present study such as $N^{\omega}$-nitro-L-arginine methyl ester (LNAME) and aminoguanidine (AG) were purchased from Sigma Chemical Co. (St. Louis, MO).

Measurements of $\mathrm{CO}$ in the effluent. Concentrations of $\mathrm{CO}$ in the effluent of the perfused liver were determined by measuring spectrophotometrically the formation of ferrous- $\mathrm{CO}$ complex of myoglobin $(\mathrm{Mb})$ (horse heart; Sigma Chemical Co.). Approximately $20 \mathrm{ml}$ of the effluent buffer was collected from the hepatic venous outlet using a gas-tight syringe $20 \mathrm{~min}$ after the start of the control perfusion. The glass cuvette with a gas-tight rubber cap was prepared for spectrophotometry of the samples. A 27-gauge long needle was inserted down to the bottom of the cuvette. After a 30-gauge short needle was inserted for air evacuation, the cuvette was filled with the sample by injecting an aliquot of the effluent (about $4.0 \mathrm{ml}$ ) through the long needle, and the air bubbles were carefully removed by purging the cuvette with injection of the rest of the effluent sample. The ferric $\mathrm{Mb}$, which was oxidized by pretreatment with potassium ferricyanide, was purified using carboxymethyl cellulose chromatography ( $\mathrm{pH} \mathrm{7.2)}$, and was stored at $-80^{\circ} \mathrm{C}$ until the day of experiments. $200 \mu \mathrm{l}$ of the $\mathrm{Mb}$ solution $(60 \mu \mathrm{M})$ was injected into the cuvette (3.0 $\mu \mathrm{M}$ at a final concentration) through the long needle so that the whole amount of $\mathrm{Mb}$ was placed at the bottom of the cuvette. After eliminating the needle and stirring the sample, the absorption spectrum was measured by a recording spectrophotometer (400-600 nm, MPS-2000; Shimazu Inc., Kyoto, Japan) equipped with a personal computer (PC 9801VX; NEC, Tokyo, Japan) which allows us to digitally process the data. The ferrous $\mathrm{CO}$ complex of $\mathrm{Mb}$ was yielded by the addition of an excess amount of dithionite ( $40 \mu \mathrm{l}$ of the $0.5-\mathrm{M}$ solution which gives $\sim 5 \mathrm{mM}$ at a final concentration in the cuvette), and the absorption spectrum was again recorded. Finally, 40 $\mu \mathrm{l}$ of the CO-saturated buffer which was kept in a gas-tight syringe $(\sim 1 \mathrm{mM})$ was injected into the reaction cuvette to saturate ferrous $\mathrm{Mb}$ with $\mathrm{CO}$, and the spectrum was recorded. Difference spectrum between the samples before and after adding dithionite was then digitally estimated. Under low concentrations of $\mathrm{CO}, \mathrm{Mb}$ in the sample after adding dithionite is a mixture of ferrous and ferrous- $\mathrm{CO}$ forms, where the difference in absorbance observed at $\lambda\left(\Delta \mathrm{A}_{\lambda}\right)$ is given as below:

$$
\begin{aligned}
\Delta \mathrm{A}_{\lambda} & =\left\{\left[\mathrm{Fe}^{2+} \mathrm{CO}\right] \epsilon_{\lambda}{ }^{\mathrm{CO}}+\left([\mathrm{Mb}]_{0}-\left[\mathrm{Fe}^{2+} \mathrm{CO}\right]\right) \epsilon_{\lambda}{ }^{\text {ferro }}\right\}-[\mathrm{Mb}]_{0} \epsilon_{\lambda}^{\text {ferri }} \\
& =[\mathrm{Mb}]_{0}\left(\epsilon_{\lambda}{ }^{\text {ferro }}-\epsilon_{\lambda}{ }^{\text {ferri }}\right)+\left[\mathrm{Fe}^{2+} \mathrm{CO}\right]\left(\epsilon_{\lambda}{ }^{\mathrm{CO}}-\epsilon_{\lambda}{ }^{\text {ferro }}\right)
\end{aligned}
$$

where, $\left[\mathrm{Fe}^{2+} \mathrm{CO}\right],[\mathrm{Mb}]_{0}, \epsilon_{\lambda}{ }^{\mathrm{co}}, \epsilon_{\lambda}{ }^{\text {ferro }}$, and $\epsilon_{\lambda}{ }^{\text {ferri }}$ are concentrations of ferrous- $\mathrm{CO}$ form, the initial concentration of $\mathrm{Mb}$ added in the cuvette $(3.0 \mu \mathrm{M})$, molar extinction coefficients at $\lambda$ of ferrous-CO, ferrous, and ferric forms, respectively. Since one of the isosbestic point between ferrous and ferric $\mathrm{Mb}$ exists at $419.1 \mathrm{~nm}$ in which $\epsilon_{419.1}{ }^{\text {ferro }}-\epsilon_{419.1}{ }^{\text {ferri }}$ $=0$, the formula can be arranged as follows:

$\left[\mathrm{Fe}^{2+} \mathrm{CO}\right]=\Delta \mathrm{A}_{419.1} /\left(\epsilon_{419.1}{ }^{\text {co }}-\epsilon_{419.1}{ }^{\text {ferro }}\right)$,

indicating that $\left[\mathrm{Fe}^{2+} \mathrm{CO}\right]$ is a linear function of $\Delta \mathrm{A}_{419.1}$. The values of $\epsilon_{419.1}{ }^{\mathrm{CO}}$ and $\epsilon_{419.1}{ }^{\text {ferro }}$ were determined by examining the absorption spectra of the same concentration of ferrous $\mathrm{Mb}$ in the presence and absence of saturated amount of $\mathrm{CO}$, respectively. To obtain the CO-saturated ferrous $\mathrm{Mb}$ solution, $40 \mu \mathrm{l}$ of the CO-saturated buffer ( $>1 \mathrm{mM}$ ) was injected into the cuvette to give a final concentration greater than 10 $\mu \mathrm{M}$. Since the dissociation constant of ferrous-CO form of $\mathrm{Mb}$ is 34.5 
$\mathrm{nM}(16)$ at room temperature ( $\mathrm{pH} 7.4), \sim 98 \%$ of the total amounts of $\mathrm{CO}$ in the $\mathrm{Mb}$-containing sample mixture binds to ferrous $\mathrm{Mb}$, and only $<2 \%$ is present as a free form, when $\mathrm{CO}$ concentrations in the samples range at $<3.0 \mu \mathrm{M}$. We therefore determined the concentration of $\mathrm{CO}$ as that of ferrous- $\mathrm{CO}$ complex of $\mathrm{Mb}$ in samples.

Primary culture of Ito cells and cGMP measurements. Isolation of Ito cells was carried out according to the previous method by Kawada et al. (17). Briefly, livers of male Wistar rats (400-450 grams) fed ad lib. on a stock diet, were treated with collagenase perfusion, and the nonparenchymal cells were pelleted by centrifugation $\left(450 \mathrm{~g}, 4^{\circ} \mathrm{C}\right.$ for $10 \mathrm{~min}$ ). An Ito cell-enriched fraction was obtained by the use of centrifugation with a triple-layered $(9,11$, and $17 \%)$ Nycodenz cushion $\left(1,400 \mathrm{~g}, 4^{\circ} \mathrm{C}\right.$ for $\left.20 \mathrm{~min}\right)$. After plating the cells, the culture medium was changed every other day. Ito cells in 5 -d culture $\left(5 \times 10^{5}\right.$ cells $)$ inoculated onto the $35-\mathrm{mm}$ collagen-coated culture dishes were used to determine the contents of cGMP. The cultured cells were washed twice with the buffer ( $137 \mathrm{mM} \mathrm{NaCl}, 2.7 \mathrm{mM} \mathrm{KCl}, 8.1 \mathrm{mM} \mathrm{Na} \mathrm{HPO}_{4} \cdot 2 \mathrm{H}_{2} \mathrm{O}$, $1.5 \mathrm{mM} \mathrm{KH}_{2} \mathrm{PO}_{4}, 0.5 \mathrm{mM} \mathrm{MgCl}_{2}$, and $0.9 \mathrm{mM} \mathrm{CaCl}_{2} \cdot 2 \mathrm{H}_{2} \mathrm{O}$, pH 7.4). After incubation with $1 \mathrm{ml}$ of the same buffer containing $0.5 \mathrm{mM} 3$ isobutyl-1-methylxanthine, an inhibitor of phosphodiesterase, for 10 min, the cells were treated with desired concentrations of $\mathrm{CO}$ for 30 min at $37^{\circ} \mathrm{C}$. $\mathrm{CO}$ concentrations in the culture medium after completing the reaction were determined by detecting the ferrous-CO complex of $\mathrm{Mb}$ as was described earlier in this study for the measurements of $\mathrm{CO}$ in the effluent from the perfused liver. To correct diffusion of $\mathrm{CO}$ in the medium to the atmosphere during the 30 -min incubation time, the decline of $\mathrm{CO}$ concentration in the culture dish were determined as a function of time (every $10 \mathrm{~min}$ after the start of incubation). The mean value for four measurements $(0,10,20$, and $30 \mathrm{~min})$ of $\mathrm{CO}$ concentrations was then defined as the actual $\mathrm{CO}$ concentration in the corresponding system. The reaction was terminated by adding $1 \mathrm{mM} \mathrm{HCl}$ and $95 \%$ ethanol. The cGMP contents in the extracts were measured by an enzyme-linked immunoassay using assay kits (RPN225; Amersham Corp., Arlington Heights, IL). Differences in the data among the groups were analyzed by one-way ANOVA combined with Scheffe-type multiple comparison test. A value of $P<0.05$ was considered significant.

\section{Results}

ZnPP-induced increase in the hepatic vascular resistance. Fig. 1 illustrates the effects of $\mathrm{ZnPP}$ on the whole organ vascular resistance and the concentration of $\mathrm{CO}$ in the effluent of the perfused liver. In the control liver, the vascular resistance was maintained in a steady state during the whole course of observation, and the concentration of $\mathrm{CO}$ in the effluent ranged at $0.23 \pm 0.09 \mu \mathrm{M}$. Accordingly, the actual flux of $\mathrm{CO}$ in the effluent ranged approximately at $0.7 \mathrm{nmol} / \mathrm{min}$ per gram of liver. In the liver treated with $1 \mu \mathrm{M} \mathrm{ZnPP}$, the resistance exhibited a time-dependent increase and reached $\sim 30 \%$ higher levels than that of the control at $30 \mathrm{~min}$. Under these circumstances, the $\mathrm{CO}$ concentration in the effluent decreased to an undetectable level. The same concentration of hematin, however, did not alter the perfusion resistance $\left(0.25 \pm 0.05 \mathrm{~cm} \mathrm{H}_{2} \mathrm{O} / \mathrm{min}\right.$ per $\mathrm{ml}$ at $30 \mathrm{~min}, n=6$ ). Pretreatment with the perfusate containing $1 \mu \mathrm{M} \mathrm{CO}$ significantly attenuated the ZnPP-induced elevation of the vascular resistance by $\sim 80 \%$. Furthermore, the CO concentration in the effluent ranged at $0.62 \pm 0.08 \mu \mathrm{M}(n=8)$ which is high enough to recover the $\mathrm{CO}$ levels in the control effluent. Since this concentration of $\mathrm{CO}$ alone did not alter the vascular resistance in the control (data not shown), the effects of exogenous $\mathrm{CO}$ supplement seem to result from its modulatory action on the ZnPP-elicited vascular response. Pretreatment with $1 \mu \mathrm{M} 8 \mathrm{Br}$-cGMP exhibited $\sim 60 \%$ inhibition of the $\mathrm{ZnPP}$ induced changes in the resistance, while the $\mathrm{CO}$ concentrations in the effluent ranged at an undetectable level.
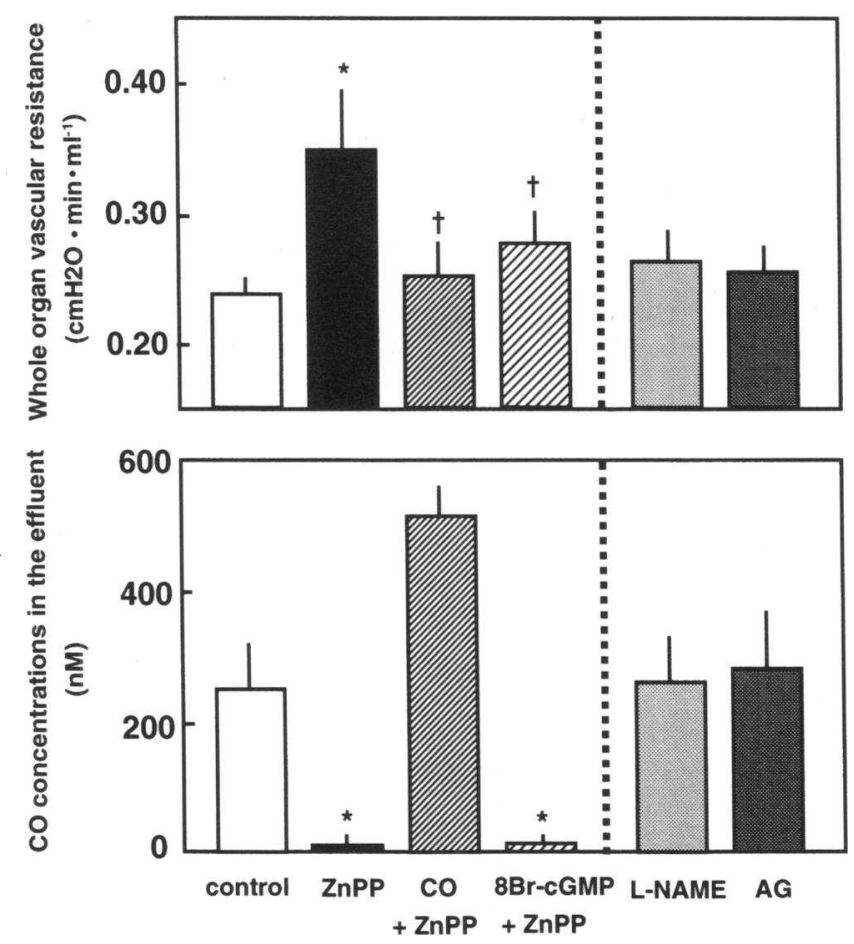

Figure 1. Effects of $\mathrm{ZnPP}$ administration ( $1 \mu \mathrm{M})$ on the hepatic vascular resistance and the concentration of $\mathrm{CO}$ in the venous effluent. Concentrations of $\mathrm{CO}$ and $8 \mathrm{Br}$-cGMP in the inlet perfusate were $1 \mu \mathrm{M}$. LNAME or AG was added at $1 \mathrm{mM}$. Data represent mean+SD of 8-12 experiments. $* P<0.05$ as compared with the control and $\dagger P<$ 0.05 as compared with the ZnPP-treated group.

Since NO is known to up-regulate cGMP, we have examined whether the hepatic vascular resistance might be elevated by NO synthase inhibitors such as L-NAME and AG, which block constitutive and inducible forms of the enzyme, respectively. Neither L-NAME nor AG at $1 \mathrm{mM}$ altered the vascular resistance, suggesting a minor role of endogenous NO production in modulation of the vascular resistance in the steady state, if any.

Inverse correlation between the vascular resistance and $\mathrm{CO}$ concentrations in the hepatic venous efflux. The finding that $\mathrm{CO}$ concentration in the effluent varied among the individual livers tempted us to examine the relationship between the vascular resistance and $\mathrm{CO}$ levels in the effluent in each experiment. Fig. 2 illustrates the correlation between the $\mathrm{CO}$ concentrations in the effluent and the whole organ vascular resistance, showing a significant inverse correlation between the level of $\mathrm{CO}$ in the effluent and the vascular resistance $\left(P<0.05, r^{2}=0.71\right)$.

$Z n P P$-induced sinusoidal constriction colocalized with Ito cells. The intrahepatic compartment responsible for the ZnPPinduced increase in the vascular resistance seems to be in microvessels according to the digital microfluorography using FITC-BSA. The early event in ZnPP-treated hepatic microvasculature ( $10 \mathrm{~min}$ after the start of the $\mathrm{ZnPP}$ administration) is a discrete pattern of sinsoidal constriction (Fig. 3, arrows 19). At the same time, the sinusoidal perfusion velocity exhibited a slight increase and then gradually decreased in a time-dependent manner, showing a $25 \%$ reduction at $30 \mathrm{~min}$ after the start of $\mathrm{ZnPP}$ administration (Fig. 4). Pretreatment with $\mathrm{CO}(1 \mu \mathrm{M})$ or with $8 \mathrm{Br}$-cGMP $(1 \mu \mathrm{M})$ significantly attenuated the ZnPP- 


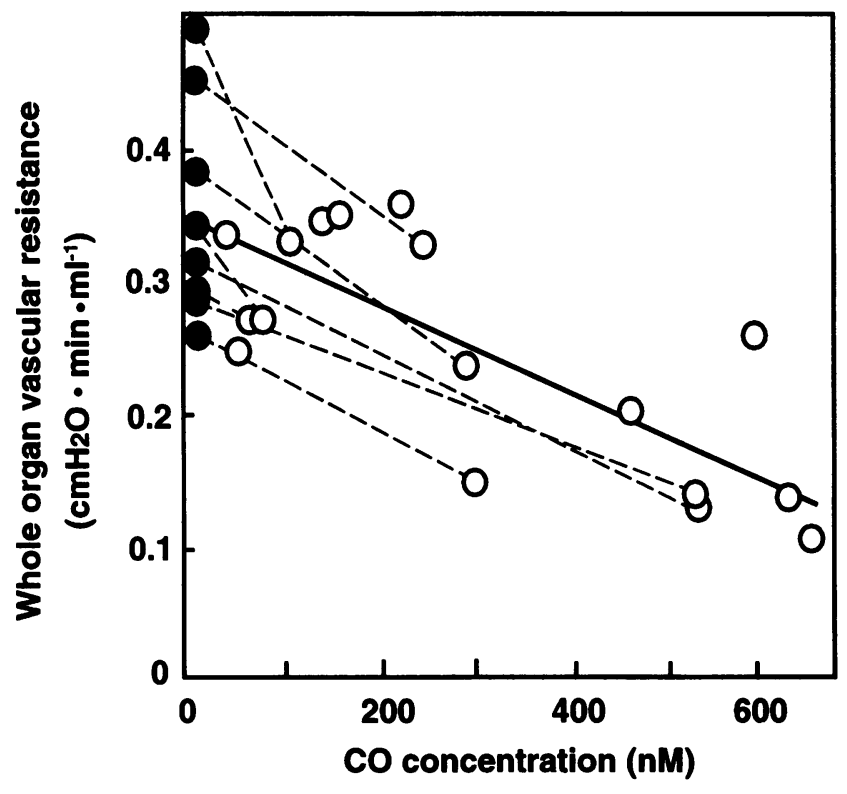

Figure 2. The correlative analysis between the $\mathrm{CO}$ concentrations in the hepatic venous effluent and the whole organ vascular resistance. Open circles $(n=17)$ denote the data measured in the control livers. In some experiments $(n=8), 1 \mu \mathrm{M} \mathrm{ZnPP}$ was administered for 30 min and samples were taken to determine the CO concentrations (closed circles). The $\mathrm{CO}$ efflux from the liver was abolished by the $\mathrm{ZnPP}$ treatment below detectable levels. Note that there is an inverse correlation between the vascular resistance and the $\mathrm{CO}$ concentration $\left(r^{2}\right.$ $=0.71, P<0.05$ ).

elicited reduction of the sinusoidal perfusion velocity. During the observation period, no significant changes in the inner diameter of central venules were observed, suggesting little possibility that postsinusoidal elements achieve major roles in the contractile mechanisms of this model.

We investigated a topographic correlation between the sites of sinusoidal constriction and the distribution of Ito cells, inasmuch as the regional constricting sites seem to correspond to the localization of Ito cells (Fig. 3, $C$ and $D$ ). Fig. 5 illustrates ZnPP-induced changes in the diameter measured at local sinusoidal segments colocalized with Ito cells and at those without Ito cells. ZnPP administration ( $1 \mu \mathrm{M})$ induced an $\sim 20 \%$ decrease in the diameter, preferentially at the local sinusoidal segments involving Ito cell-associated vitamin A autofluorescence. The $\mathrm{ZnPP}$-induced sinusoidal constriction was abolished by a continuous infusion of $\mathrm{CO}(1 \mu \mathrm{M})$, and was partly inhibited by pretreatment with $8 \mathrm{Br}-\mathrm{cGMP}(1 \mu \mathrm{M})$.

To differentiate the direct vasoactive effects of $\mathrm{ZnPP}$ at the sinusoidal level from its effects at the level of portal venules, we investigated the effects of PE on sinusoidal hemodynamics in situ as well as on the whole organ perfusion. Administration of PE ( $500 \mathrm{nM})$ induced a significant increase in the vascular resistance $\left(0.35 \pm 0.09 \mathrm{cmH}_{2} \mathrm{O} / \mathrm{min}\right.$ per $\left.\mathrm{ml}, n=6\right)$ which was equivalent to that elicited by $1 \mu \mathrm{M} \mathrm{ZnPP}$ (Fig. 1). However, the sinusoidal response exhibited quite different pictures between PE- and ZnPP-treated livers. Namely, as far as the perfused lobules were observed by FITC-BSA-assisted digital microfluoroangiography, there were no sinusoidal narrowing patterns which were typically observed in the ZnPP-treated liver (Fig. 5). These results imply that the vascular sites responsible for the PE-induced elevation of vascular resistance may be the proximal portal veins or venules rather than sinusoids, confirming the previous observation by Zhang et al. (18). Such a difference between the two groups was observed in the state of macroscopic perfusion which was assessed by the trypan blue technique. In the ZnPP-treated liver, the intrahepatic distribution of the dye color exhibited uniform and homogeneous patterns. By contrast, the PE-treated liver was stained in patches and the fluorescence intensity exhibited a marked heterogeneity even among the perfused lobules, indicating nonuniform and heterogenous liver perfusion. Taken together, the present findings suggest that sinusoidal constriction, rather than presinusoidal constriction, contributes to the $\mathrm{ZnPP}$-induced increase in the hepatic vascular resistance.

Up-regulation of cGMP in cultured Ito cells in response to $C O$. Colocalization of Ito cells with the regional sites of the ZnPP-elicited sinusoidal constriction and modulatory effects of $\mathrm{CO}$ and $8 \mathrm{Br}$-cGMP lead us to hypothesize that Ito cells might involve the local vasorelaxing mechanism operated by the $\mathrm{CO}$ dependent activation of guanylate cyclase. We therefore investigated the CO-elicited response of cGMP, a cyclic nucleotide which relaxes cytoskeleton of Ito cells (17). Fig. 6 illustrates the effects of $\mathrm{CO}$ which were applied exogenously to primary cultured Ito cells on the amounts of cGMP. The application of the CO-containing buffer induced a dose-dependent increase in cGMP contents in Ito cells. Since the elevation of cGMP has been considered a relaxing mechanism for Ito cells (17), the present results suggest that these cells could be relaxed in response to extracellularly applied $\mathrm{CO}$. The minimum concentration of $\mathrm{CO}$ which evoked significant increase in cGMP ranged at $20 \mu \mathrm{M}$, which was $\sim 100$-fold higher than that detected in the effluent of the control perfused liver. $\mathrm{CO}$ at $50 \mu \mathrm{M}$ elicited a greater increase in cGMP that was almost equivalent to that elicited by $100 \mu \mathrm{M}$ sodium nitroprusside. On the other hand, $\mathrm{ZnPP}$ at $1 \mu \mathrm{M}$ did not alter the levels of cGMP in cultured Ito cells, suggesting that an inhibitory action of this reagent on guanylate cyclase (19) in Ito cells may not contribute to the sinusoidal constriction under the current experimental conditions.

\section{Discussion}

The present study together with our previous communication (7) has first provided substantial evidence that constitutive levels of CO generation play a crucial role in maintenance of hepatic sinusoidal tone in a relaxing state. In agreement with the previous observations $(1,20)$, the major source of $\mathrm{CO}$ in the liver is heme oxygenase, since $\mathrm{CO}$ detected in the effluent of the liver were abolished by the administration of $1 \mu \mathrm{M} \mathrm{ZnPP}$, a potent inhibitor of the enzyme. In the control liver, parenchymal cells are considered the major cellular compartment of heme oxygenase reaction which yields $>85 \%$ of the total flux of $\mathrm{CO}$ and biliverdin in vivo (21). According to the current results obtained from the perfused liver preparation, the output of $\mathrm{CO}$ released from the whole liver into circulatory system ranged approximately at $2.2 \mathrm{nmol} / \mathrm{min}$ per 100 gram of rat weight, assuming that the liver weight ranges at $2.8 \%$ of the rat body weight $(22)$. This estimation matches roughly the rate of spontaneous generation of bilirubin, an end product of heme degradation pathway, in fresh isolated hepatocytes $(3.0 \mathrm{nmol} /$ min per 100 gram of rat weight), based on the assumption that rat liver contains an average of $5 \times 10^{8}$ parenchymal cells $/ 100$ 

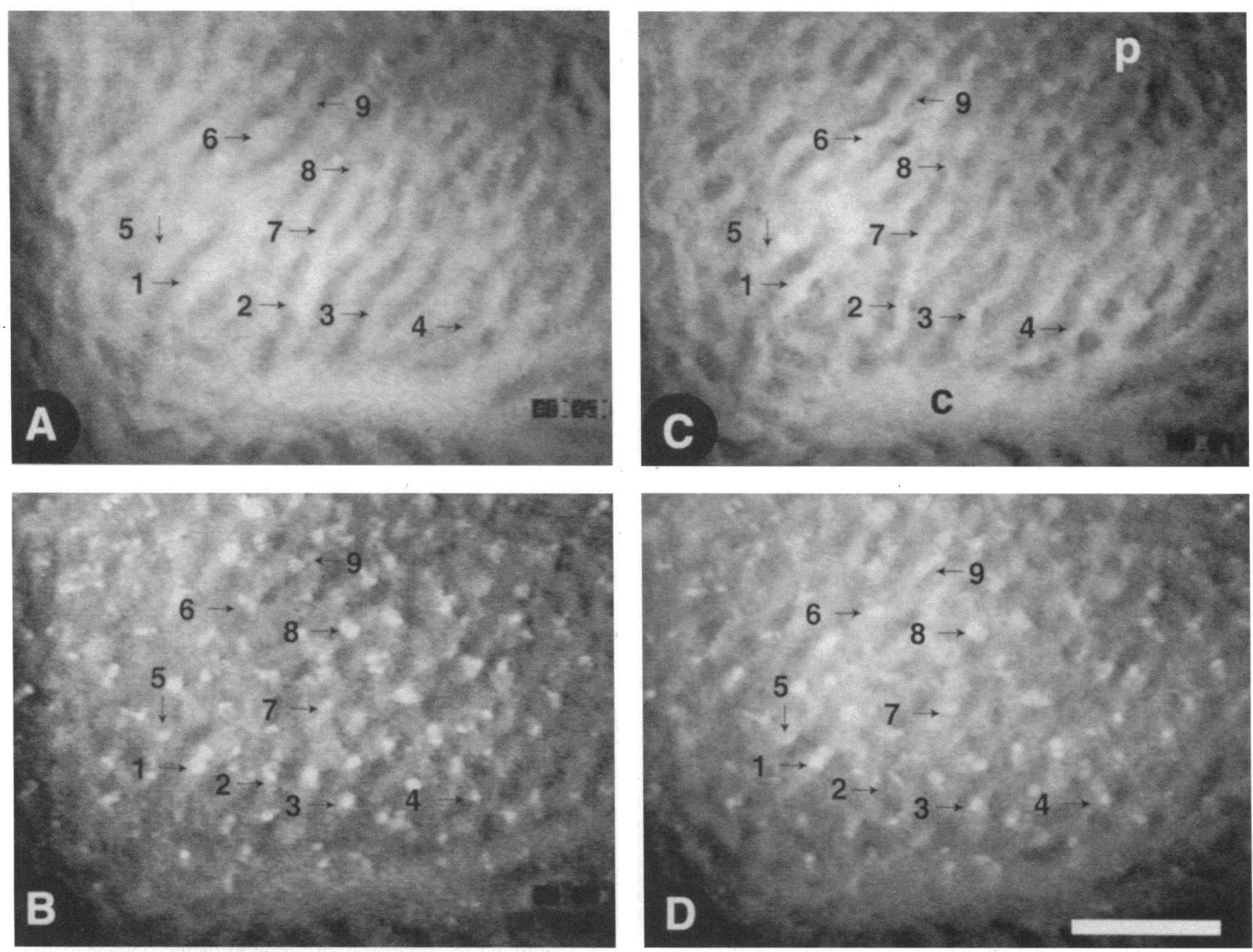

Figure 3. Representative pictures of ZnPP-induced sinusoidal constriction and its topographic relationship with the localization of Ito cells. Parts $\mathrm{A}$ and B illustrate microfluorographs during the injection of FITC-labeled albumin before, and $10 \mathrm{~min}$ after the start of $\mathrm{ZnPP}$ administration at 1 $\mu \mathrm{M}$, respectively. Intrahepatic localization of Ito cells can be identified by vitamin A autofluorescence, which is visualized at $450 \mathrm{~nm}$ emission under epi-illumination at $360 \mathrm{~nm}$. Since vitamin A autofluorescence is rapidly photobleached, the exposure time to visualize Ito cells was automatically controlled to $1 \mathrm{~s}$ using an electric shutter. Vitamin A microfluorographs were stored in the computer and were digitally overlaid to the corresponding microvascular images. Parts $\mathrm{C}$ and D show such superimposed images before and after the start of ZnPP administration at $1 \mu \mathrm{M}$, respectively. Note that individual sinusoids (arrows 1-9) represent marked constriction, $p$, periportal regions; $c$, central venules. Bar denotes $100 \mu \mathrm{m}$.

grams of body weight as previously described (23). Taking into accounts these findings, our results suggest that $\mathrm{CO}$ constitutively released from hepatic parenchyma may influence local vascular resistance serving as a tissue-derived vasorelaxant in the liver.

The local vascular sites responsible for the ZnPP-induced elevation of vascular resistance seems to be sinusoidal microvessels rather than the proximal portal vessels with large sizes to which PE exerts vasoconstriction and a resultant heterogenous patterns of macroscopic vascular perfusion (18). It should be noted that $\mathrm{ZnPP}$ administration evoked discrete patterns of sinusoidal constriction, the sites of which closely corresponded to the distribution of Ito cells, the liver-specific microvascular pericytes (24). Since the ZnPP-induced elevation of the vascular resistance was attenuated by supplement with $\mathrm{CO}$ or with $8 \mathrm{Br}$-cGMP, we hypothesized that Ito cells may be responsible for lowering the sinusoidal resistance via the vasorelaxing mechanism involving CO-dependent activation of guanylate cyclase. There are several lines of evidence in the present study which support the hypothesis: exogenously administered cGMP partially attenuated the ZnPP-induced elevation of the vascular resistance. In addition, exogenous $\mathrm{CO}$ application at millimolar levels significantly up-regulated cGMP in cultured Ito cells. Furthermore, attenuation of the ZnPP-elicited regional sinusoidal constriction concomitant with the elevation of vascular resistance by $8 \mathrm{Br}$-cGMP occurred without increasing the $\mathrm{CO}$ concentration in the efflux solution. There results suggest that $\mathrm{CO}$ endogenously generated by heme oxygenase may activate guanylate cyclase in Ito cells and thereby maintain sinusoids in a dilated state.

Of interest is that endogenous NO production is unlikely to be involved in the vasorelaxing mechanism in hepatic sinusoids, inasmuch as neither constitutive nor inducible NO synthase inhibitors did alter the vascular resistance and the sinusoidal hemodynamics. Since the reactivity of NO with heme proteins is much higher than that of $\mathrm{CO}$ in vitro (25), there is a possibility that the concentration of NO required for sinusoidal constriction in the local compartment (e.g., Disse space) might be 


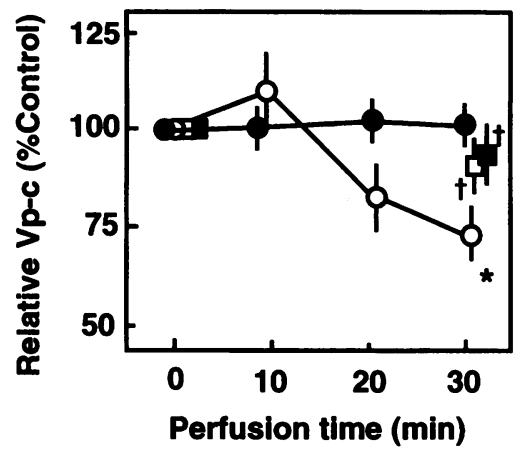

Figure 4. Time history of sinusoidal perfusion velocity $(V p-c)$ during the administration of $1 \mu \mathrm{M}$ $\mathrm{ZnPP}$. Measurements in three different lobules were carried out in a single experiment. Data were expressed as the relative velocity versus corresponding control values (percent control), and represent mean $\pm S D$ of five experiments.

(Closed circles) control. (Open circles) $1 \mu \mathrm{M} Z \mathrm{ZnPP}$. (Closed squares) $1 \mu \mathrm{M} \mathrm{CO}+1 \mu \mathrm{M}$ ZnPP. (Open squares) $1 \mu \mathrm{M} 8 \mathrm{Br}-\mathrm{c}-\mathrm{GMP}+1 \mu \mathrm{M}$ ZnPP. $* P<0.05$ as compared with the control and $\dagger P<0.05$ as compared with the ZnPP-treated group.

extremely low as compared with that of $\mathrm{CO}$. Recent observation by Bautista et al. showing the interaction between superoxide anion and NO in the perfused liver (26) could give a possible explanation for this hypothesis. Namely, under normal conditions, $\mathrm{NO}$ or superoxide concentrations in the liver may virtually be negligible, presumably because they counteract each other to maintain a normal balance between them. Under these circumstances, a nonradical monoxide such as $\mathrm{CO}$ may serve as an effective agonist for cGMP up-regulation. The actual sinusoidal perfusion in vivo is influenced by diverse factors such as neural regulation, the hepatic arterial tone, and the dynamics of intestinal circulation that are not involved in the perfused system. It is therefore likely that perturbation of endogenous NO generation may alter the sinusoidal tone in vivo, as was shown by

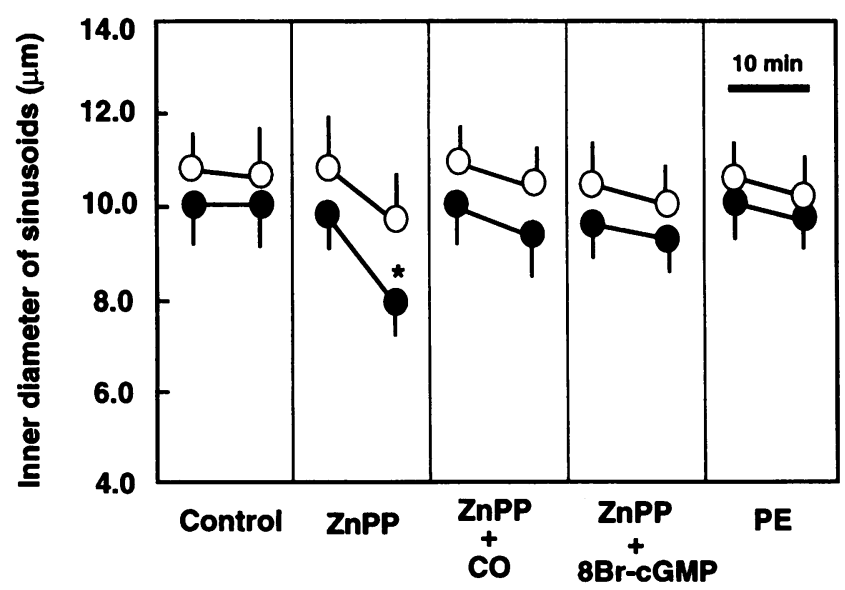

Figure 5. The ZnPP-induced alterations in the sinusoidal diameter and the effects of exogenously administered $\mathrm{CO}$ and $8 \mathrm{Br}$-cGMP. Closed and open circles denote the data recorded at regional sinusoidal domains colocalized with Ito cells which are identified by their vitamin A autofluorescence and those without Ito cells, respectively. PE, the phenylephrine ( $500 \mathrm{nM}$ at a final concentration)-treated group. At least 15 sinusoids were evaluated in a single experiment. Data represent mean $\pm S D$ of measurements of $>60$ sinusoids from 5 liver preparations. Since the lobules observed were not perfused occasionally in the PEtreated livers because of heterogenous feature of the macroscopic perfusion, measurements were carried out only when the lobules observed were perfused with FITC-BSA. $* P<0.01$ as compared with the values at time 0 in other groups.

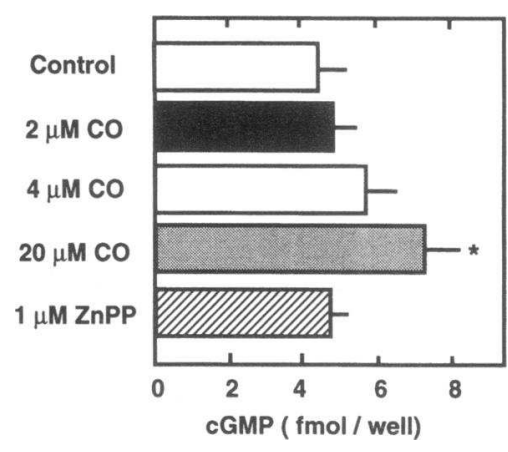

Figure 6. Effects of the application of $\mathrm{CO}$ on cGMP levels in primary cultured Ito cells. Data represent mean $+\mathrm{SD}$ of eight different sets of experiments. $* P<0.05$ as compared with the control. Note that $\mathrm{CO}$ elicits upregulation of cGMP in a dose-dependent manner, showing a significant increase at 20 $\mu \mathrm{M}(P<0.05)$.

Nishida et al. (27). Although such an intravital study should further be evaluated, the current results shed light on the possible physiologic role of tissue-derived $\mathrm{CO}$ as an alternative cGMP-dependent microvascular modulator in the liver.

Another hypothesis to be taken into account as a CO-dependent vasorelaxing mechanism in sinusoids is the possible involvement of the cGMP-independent pathway. Several findings in the current study support this possibility: first, the minimum $\mathrm{CO}$ concentration which was required to elicit a significant increase in cGMP in cultured Ito cells was at least 100-fold higher than that detected in the effluent of the control perfused liver. Secondly, the effects of $8 \mathrm{Br}$-cGMP on the $\mathrm{ZnPP}$-induced increase in the vascular resistance was limited only to the $60 \%$ inhibition, suggesting the presence of alternative mechanisms for CO-mediated vasorelaxation. Such an unknown action of $\mathrm{CO}$ which involves cGMP-independent signal transduction mechanism has recently been postulated by Kourembanas et al. (28) who reported that exogenously applied CO can modulate the expression of endothelin and growth factors independently of cGMP. Recent observation by Rich et al. has provided evidence that $\mathrm{CO}$ elicits an increase in potassium current and thereby hyperpolarizes the resting membrane potential in rabbit corneal epithelial cells (29). Since the hyperpolarizing effects of $\mathrm{CO}$ has also been reported in other types of cells such as intestinal smooth muscle cells (30), electrophysiological properties of cultured Ito cells and the effect of $\mathrm{CO}$ on transmembrane currents should be evaluated to reveal a novel vasorelaxing mechanism of $\mathrm{CO}$. Moreover, since sinusoidal endothelial cells per se may serve as another possible contractile element which alters fluid filtration via regulation of tone in their sieve plates (31), it is also necessary to elucidate involvement of such Ito cell-independent mechanisms for $\mathrm{CO}$-mediated regulation of sinusoidal resistance. Although the $\mathrm{CO}$-mediated mechanisms for sinusoidal relaxation have not fully been revealed at the present moment, our observation that $\mathrm{CO}$ endogenously generated by heme oxygenase reaction exerts an modulatory action on sinusoidal relaxation not only gives a clue to the mechanism by which the liver can maintain an extremely low level of vascular resistance as compared to that in other organs, but may also provide an insight into a novel physiologic role of heme oxygenase as an active vasorelaxing machinery in addition to its established role for heme degradation.

\section{Acknowledgments}

The authors thank Dr. Norifumi Kawada for assistance to establish primary cultured Ito cells for cGMP measurements. A preliminary 
account pertinent to a portion of this work was presented in the Annual Meeting in Digestive Disease Week on 15 May 1995, in San Diego, CA.

This work was supported by Grant-in-Aid for Scientific Research from the Ministry of Edication, Science, and Culture of Japan, and by grants from Keio University School of Medicine and from Research Foundation for Opto-Science and Technology.

\section{References}

Maines, M. 1988. Heme oxygenase: function, multiplicity, regulatory mechanisms, and clinical application. FASEB (Fed. Am. Soc. Exp. Biol) J. 2:25572568.

2. Yoshida, T., and G. Kikuchi. 1978. Features of the reaction of heme degradation catalized by the reconstituted microsomal heme oxygenase system. J. Biol. Chem. 253:4230-4236.

3. Vedernikov, Y. P., T. Gräser, and A. F. Vanin. 1989. Similar endotheliumindependent arterial relaxation by carbon monoxide and nitric oxide. Biomed. Biochim. Acta. 48:601-603.

4. Brüne, B., and V. Ullrich. 1987. Inhibition of platelet aggregation by carbon monoxide mediated by activation of guanylate cyclase. Mol. Pharmacol. 32:497504.

5. Verma, A., D. J. Hirsh, C. E. Glatt, G. V. Ronnett, and S. H. Snyder. 1993 Carbon monoxide: a putative neural messenger. Science (Wash. DC). 259:381384.

6. Zhuo, M., S. A. Small, E. R. Kandel, and R. D. Hawkins. 1993. Nitric oxide and carbon monoxide produce activity-dependent long-term synaptic enhancement in hippocampus. Science (Wash. DC). 260:1946-1950.

7. Suematsu, M., S. Kashiwagi, T. Sano, N. Goda, Y. Shinoda, and Y. Ishimura. 1994. Carbon monoxide as an endogenous modulator of hepatic vascular perfusion. Biochem. Biophys. Res. Commun. 205:1333-1337.

8. Suematsu, M., H. Suzuki, H. Ishii, S. Kato, T. Yanagisawa, H. Asako, M Suzuki, and M. Tsuchiya. 1992. Early midzonal oxidative stress preceding cell death in hypoperfused rat liver. Gastroenterology. 103:994-1001.

9. Suematsu, M., H. Suzuki, H. Ishii, S. Kato, H. Hamamatsu, S. Miura, and M. Tsuchiya. 1992. Topographic dissociation between mitochondrial dysfunction and cell death during low-flow hypoxia in perfused rat liver. Lab. Invest. 67:434 442.

10. Suzuki, H., M. Suematsu, H. Ishii, S. Kato, H. Miki, M. Mori, Y. Ishimura T. Nishino, and M. Tsuchiya. 1994. Prostaglandin $E_{1}$ abrogates early reductive stress and zone-specific paradoxical oxidative injury in hypoperfused rat liver. $J$. Clin. Invest. 93:155-164.

11. Suematsu, M., M. Oda, H. Suzuki, H. Kaneko, T. Furusho, S. Masushige and M. Tsuchiya. 1993. Intravital and electron microscopic observation of Ito cells in the rat hepatic microcirculation. Microvasc. Res. 46:28-42.

12. Jungermann, K. 1987. Regulation von Stoffwechsel und Hämodynamik der Leber durch die hepatischen Nerven. Z. Gastroenterol. 25(Suppl. 1):44-54.

13. Reilly, F. D., R. S. McCuskey, and E. V. Cilento. 1981. Hepatic microvascular mechanisms. I. Adrenergic mechanisms. Microvasc. Res. 21:103-116.

14. Grossman, H. J., V. L. Grossman, and P. S. Bhathal. 1992. Enhanced vasoconstrictor response of the isolated perfused cirrhotic rat liver to humoral vasoconstrictor substances found in portal venous blood. J. Gastroenterol. Hepatol. 7:283-287.
15. Tanaka, A., K. Katagiri, M. Hoshino, T. Hayakawa, K. Tsukada, and T. Kakeuchi. 1994. Endothelin-1 stimulates bile acid secretion and vesicular transport in the isolated perfused rat liver. Am. J. Physiol. (Gastrointest. and Liver Physiol.) 266:G324-G329.

16. Antonini, E., and M. Brunori. 1971. Hemoglobin and myoglobin in their reactions with ligands. In Frontiers of Biology. A. Neuberger and E. L. Tatum, editors. North-Holland Publishing Co., London. 219-234.

17. Kawada, N., T.-A. Tran-Thi, H. Klein, and K. Decker. 1993. The contraction of hepatic stellate (Ito) cells stimulated with vasoactive substances: possible involvement of endothelin 1 and nitric oxide in the regulation of the sinusoidal tonus. Eur. J. Biochem. 213:815-823.

18. Zhang, J. X., W. Pegoli, Jr., and M. G. Clemens. 1994. Endothelin-1 induces direct constriction of hepatic sinusoids. Am. J. Physiol. (Gastrointest. Liver Physiol.) 266:G624-G632.

19. Ignarro, L. J., B. Barrot, and K. S. Wood. 1984. Regulation of soluble guanylate cyclase activity by porphyrins and metalloporphyrins. J. Biol. Chem. 259:6201-6207.

20. Landaw, S. A., E. W. Callahan, Jr., and R. Schmid. 1970. Catabolism of heme in vivo: comparison of the simultaneous production of bilirubin and carbon monoxide. J. Clin. Invest. 49:914-925.

21. Bissell, D. M., L. Hammaker, and R. Schmid. 1972. Hemoglobin and erythrocyte catabolism in rat liver: the separate roles of parenchymal and sinusoidal cells. Blood. 40:812-822.

22. Stock, R. J., E. V. Cilento, R. S. McCuskey. 1989. A quantitative study of fluorescein isothiocyanate-dextran transport in the microcirculation of the isolated perfused rat liver. Hepatology. 9:75-82.

23. Weibel, E. R., W. Stäubli, H. R. Gnägi, and F. A. Hess. 1969. Correlated morphometric and biochemical studies on the liver cell. I. Morphometric model, stereologic methods, and normal morphometric data for rat liver. J. Cell Biol. 42:68-79.

24. Pinzani, M., P. Failli, C. Ruocco, A. Casini, S. Milani, E. Baldi, A. Giotti. 1992. Fat-storing cells as liver-specific pericytes: spatial dynamics of agoniststimulated intracellular calcium transients. J. Clin. Invest. 90:642-646.

25. Kosaka, H., M. Watanabe, H. Yoshihara, N. Harada, and T. Shiga. 1992. Detection of nitric oxide production in lipopolysaccharide-treated rats by ESR using carbon monoxide hemoglobin. Biochem. Biophys. Res. Commun. 184:11191124

26. Bautista, A. P., and J. J. Spitzer. 1994. Inhibition of nitric oxide formation in vivo enhances superoxide release by the perfused liver. Am. J. Physiol. (Gastrointest. Liver Physiol.) 266:G783-G788.

27. Nishida, J., R. S. McCuskey, D. McDonnell, and E. S. Fox. 1994. Protective role of NO in hepatic microcirculatory dysfunction during endotoxemia. Am. J. Physiol. (Gastrointest. Liver Physiol.) 267:G1135-G1141.

28. Kourembanas, S., L. P. McQuilan, G. K. Leung, and D. V. Faller. 1993. Nitric oxide regulates the expression of vasoconstrictors and growth factors by vascular endothelium under both normoxia and hypoxia. J. Clin. Invest. 93:99104.

29. Rich, A., G. Farrugia, and J. L. Rae. 1994. Carbon monoxide stimulates a potassium-selective current in rabbit corneal epithelial cells. Am. J. Physiol. (Cell Physiol.) 267:C435-C442.

30. Ratten, S., and S. Chakder. 1993. Inhibitory effect of CO on intestinal ana sphincter: heme oxygenase inhibitor inhibits NANC relaxation. Am. J. Physiol. (Gastrointest. Liver Physiol. 28): 265:G799-G804.

31. Wisse, E., R. B. De Zanger, K. Charels, P. Van Der Smissen, and R. S. McCuskey. 1985. The liver sieve: considerations concerning the structure and function of endothelial fenestrae, the sinusoidal wall and the space of Disse. Hepatology. 5:683-692. 